$\Delta 109$

PULMONARY DEPOSITION OF SALBUTAMOL AEROSOL DELIVERED BY METERED DOSE INHALER (MDI), JET NEBULLIZER AND ULTRASONIC NEBULIZER IN MECHANICALLY
VENTILATED RABBITS. Tai F.Fok, Mazan M.Al-Essa, Shelly Monkman, Myrna VENTILATED RABBITS. Tai F. Fok, Mazan M.Al-Essa, Shelly Monkman, Myrna
B.Dolovich, Geoffrey Coates, Barry Bowen, Haresh M. Kirpalani Dept of B.Dolovich, Geoffrey Coates, Barry Bowen, Haresh M. Kirpalani Dept of
Pediatrics, Medicine \& Nuclear Medicine, McMaster University, Hamilton, Ontario, Canada

Technetium-99n labelled Salbutamol was administered through a tracheostomy to ventilated rabbits by either an MDI (5) Canada) (Group1, $\mathrm{n}=7$ ); or by nebulization (100 $\mu \mathrm{g} / \mathrm{kg}$ in $3 \mathrm{ml}$ Technetium-99m labelled 5\% al bumin). Nebulization was carried out for $20 \mathrm{~min}$. with a Jet (Hudson, USA) (Group 2, $n=11$ ) or Ul trasonic device (Siemens, Smeden) using either a standard (Group $3, n=6$ ) or a small (Group 4, $n=7$ ) reservoir. Lung deposition was est imated by gamala counting of the autopsy lung specimens: mean(sd):

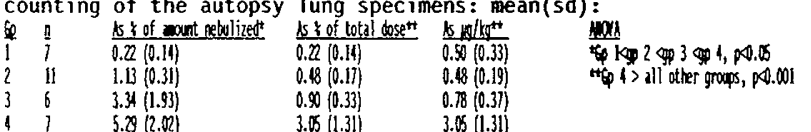

Salbutamol was uniformly distributed in the lungs in group 1 and 2 Salbutamol was uniformly distributed in the lungs in group 1 and 2, but showed a predilection for the right anterior azygous lobes and the central lung regions in group 3 and 4 . Conclusion: in delivering greater lung deposition but less uniform distribution than either Jet or MDI. Reducing reservoir volume enhances its efficiency of delivery further, but also yields differential deposition in lobes.

\section{$\Delta \mathbf{1 1 0}$}

SERUM TRANSFERRIN RECEPTOR ( $T$ ER) AND ERYTHROPOIETIN (EPO) AS INDICATORS OF ERYTHROPOIESIS IN CHILDREN WITH NEWLY DIAGNOSED ACUTE LYMPHOBLASTIC LEUKEMIA (ALL)

Sanna M. Kivivuori, Lasse Viinikka, Martti A. Sijmes

Children's Hospital, University of Helsinki, Helsinki

The initial depression of erythropoiesis followed by a rapid stimulation of erythropoiesis in children with newly diagnosed ALL may serve as a model to study $T f R$ and Epo as indicators of erythropoiesis. We studied weekly the blood hemoglobin and reticulocyte counts, TfR and Epo from 35 children with newly diagnosed ALL during 12 weeks from diagnosis. The mean age of the patients was 6.1 years. The patients were treated according to the Scandinavian ALL protocols. Serum $T f R$ and Epo concentrations were measured py respectively. The mean weekly Tf concentrations were 2.8 respectively. The mean weekly TfR concentrations were 2.8
$\pm 0.2 \mathrm{mg} / \mathrm{l}$ (SEM) at diagnosis. They gradually decreased to $2.1 \pm 0.2 \mathrm{mg} / 1$ at 3 weeks. Thisafter, the values increased and reached the maximal level at 8 weeks $(4.9 \pm 0.5 \mathrm{mg} / 1)$. mean values for reticulocyte counts was similar; $1.3 \pm 0.2 \%$ at diagnosis, $0.3 \pm 0.05 \%$ at 2 weeks and $4.7 \pm 1.3 \%$ at 8 weeks. In contrast, Epo levels were elevated and behaved differently. The mean value was $330 \mathrm{IU} / \mathrm{L}$ at diagnosis. After the therapy started the values gradually decreased by week 5 and remained stable thereafter (mean values 79-111 IU/L). Under these conditions we conclude that 1) TfR level reflects the rate of erythropoiesis, and 2) TfR level is undependent on the Epo levels.

\section{$\triangle 111$}

A HIGHLY PREVALENT SPLICE SITE MUTATION IN THE CYSTATHUONINEB-SYNTHASE GENE IS ASSOCIATED WITH POOR VITAMIN B6 RESPONSE IN HOMOCYSTINURIA

Hans G. Koch, Kurt Ullich, Thomas Deufel, and Erik Harms

Kinderklinik der Westfälischen Wilhelms-Universität Münster, FRG

Screening for mutations of the cystathionine- $\beta$-synthase (CBS) gene of homocystinuric patients we detected a splice site mutation (A1224-2C) which results in skipping of an entire $135 \mathrm{bp}$ exon. This mutation was reported recently by Kozich and Kraus (Hum.Mut. 1,113-123;1992) and found to be associated with vitamnin B6responsiveness in a compound heterozygous patient with mild clinical course. We established a SSCP assay to screen for this distinct splice site mutation of the CBS gene. So far, we have detected this mutation on $S$ out of $28(17.8 \%)$ affected chromosomes from nonrelated homocystinuric patients. Three patients were compound heterozygous. One male offspring of non-consanguinous parents of German origin was homozygous. In contrast to the patient described by Kozich and Kraus, this patient was clearly nonresponsive even when treated with high dose vitamin B6. He showed a severe clinical phenotype with early ocular involvement and mental retardation. Two of the three compound heterozygotes detected were also vitamin B6 nonresponders with severe phenotypes. From this we conclude that the splice site mutation A1224-2C represents a frequent defect of the CBS gene causing homocystinuria which is nonresponsive to vitamin B6 treatment. Only when combined with certain other mutations in compound heterozygotes, this second allel may contribute to a milder phenotype and confer vitamin B6 responsiveness.

112

OUTCOME OF VERY PRETERM SMALL FOR DATE INFANTS. Joke H Kok', S P Verloove-Vanhorick, R Brand. Dept of Neonatology*, Academic Medical Centre, Amsterdam.

Objective: To investigate the effect of intra-uterine growth retardation on mortality and developmental outcome at 5 years of age in a cohort of very preterm infants.

Patients and methods: From a national collaborative study of 1338 liveborn infants of $<32$ weeks and/or < 1500 grams, 765 infants were selected on gestational age (GA) between 25 and 32 weeks, kaukasian race, and without having congenital malformations. Infants were classified according to Kloosterman's percentiles. Small for gestational age $(S G A)$ infants $(<10$ th centile) were compared with appropriate for gestational age (AGA) infants (25-75th centile).

Results: Neonatal mortality and mortality at 5 years of age is significantly higher in SGA compared with AGA after stratifying for $C$ section or vaginal delivery (OR 0.55 $(0.32-0.95) p=0.02)$, a similar result is found after taken into account $G A$, sex, multiple pregnancy (MPR) as confounders. Overall outcome at 5 year expressed in handicap rate (WHO definition) is not significantly different (SGA 20\% vs AGA 13\% $(p=0.17))$. However, cerebral palsy is less frequent in SGA infants than in AGA infants $(7.2 \%$ vs $14.9 \%$ ), while retardation of gross motor skills is more frequent in SGA infants (15.7\% vs $7.4 \%$ ). Mental development, language/speech development and need for special education seems to be worser in SGA infants, but is not statistically significantly different (OR 0.85) after correction for confounders GA, sex, and MPR. Conclusion: Mortality in SGA infants is about twice as high as compared to AGA infants in the first 5 years. Overall developmental outcome in the SGA survivors at 5 year appears noc to be different from AGA infants.

\title{
- 113
}

THE CHRONIC FORM OF COXSACKIE VIRUS INFECTION OF CHILDREN WITH INSUIIN DEPENDENT DIABETES MELLITUS.

Tatyana N. Konopleva, Lenaera S. Lozovskaja

Scientific Research Institute of Pediatrics, Russian

Academy of Medical Science, Moscow, Russia.

We examined 100 children with insulin dependent diabetes mellitus (IDDM) and 30 healthy children by virological method (reaction of indirect immunofluorescention). We founded that Coxsackie A and B viruses are discovered in sediment urine cells more of ten in children with IDDM as at the beginning of disease (79.3\%) as at longtime disease (52.2\%) in comparison with children control group (16.1\%). After the repeated selected exam sick children during the interval from 5 till 18 months we founded that 5 children had the persistence of determined Coxsackie viruses (A5, A16, B2, B3, B4). The examination of autopsia materials of 7 died children with IDDM shown that Coxsackie viruses was founded in tissues of pancreas, thymus, kidneys. Therefore, this data prove the participation of Coxsackie viruses in children InDM etiology.

114 DIOXYN AND POLYCHLORINATED BIPHENYL LEVELS IN PLASMA AND HUMAN MILK OF
WOMEN IN . RELATION TO THEIR LIVING AREA IN THE. NETHERLANDS. COI C Koopman-Esseboom', Marcel Huisman², Nynke Weisglas-Kuperus', Rudy E. Boersma ${ }^{2}$, Maria A. de Ridder ${ }^{3}$ Pieter J. Sauer'. 'Dep of Paediatr, Div of Neonatol, 'Inst of Epid and Biost, Erasmus Univ/Sophia Children's Hosp, Rotterdam. "Dep of Obst and Gynaec, Univ of Groningen, the Netherlands. Dioxins and polychlorinated biphenyls (PCBs) are ubiquitous toxic
compounds in the environment that may have adverse effects on the neurodevelopment of infants. We examined if women living in an industrialized area had higher dioxin or PCB levels compared to women dam city and in surrounding, highly industrialized areas in the in the north. PCB levels were investigated in plasma. In human milk, PCB as well as dioxin levels were measured.

\begin{tabular}{|l|l|l|l|l|l|l||}
\hline & \multicolumn{3}{|l|}{ Ln PCB 118 plasma $(N=406)$} & \multicolumn{2}{|l|}{ Ln Dioxin-rEQ milk (N=171) } \\
\hline Variable & $B$ & S.E. & $P$ & P & S.E. & P \\
\hline Rotterdam* & 0.12 & 0.05 & .02 & 0.15 & 0.06 & .01 \\
\hline Industrial* & 0.23 & 0.08 & .003 & 0.19 & 0.09 & .03 \\
\hline
\end{tabular}

* Baseline area = Groningen. Part of the multiple regression analysis: other significant covariates:age of the women, fat percentage of
milk, weeks of given breast-feeding to older children, smoking. We conclude that infants born in the western industrialized area of utero and during breast-feeding, compared to infants born in a semiurban area in the north. Although diet is estimated as the main source of exposure, inhaling and dermal absorption might be additional routes 